\title{
Leydig cell clustering and Reinke crystal distribution in relation to hormonal function in adult patients with testicular dysgenesis syndrome (TDS) including cryptorchidism
}

\author{
Rikke R. Soerensen, ${ }^{1,2}$ Trine H. Johannsen, ${ }^{1}$ Niels E. Skakkebaek, ${ }^{1}$ Ewa Rajpert-De Meyts ${ }^{1}$ \\ ${ }^{1}$ Department of Growth and Reproduction, and International Center for Research and Research Training on Endocrine \\ Disrupting Effects on Male Reproduction \& Child Health (EDMaRC), Copenhagen University Hospital (Rigshospitalet), \\ Copenhagen, Denmark, ${ }^{2}$ Department of Pathology, University Hospital Herlev, Herlev, Denmark
}

\begin{abstract}
OBJECTIVE: Testicular dysgenesis syndrome (TDS) comprises testicular germ cell cancer, cryptorchidism and some cases of male infertility and hypospadias, which can be linked to impairment of intrauterine gonadal development. Among histological signs of TDS, large Leydig cell (LC) clusters (micronodules) are frequently present. This study aimed to investigate possible associations of $\mathrm{LC}$ micronodules with the presence of Reinke crystals and hormonal function of LCs, the latter primarily reflected by serum concentrations of luteinising hormone (LH) and testosterone, in patients with TDS. DESIGN: A retrospective study of 101 andrological patients with TDS (infertility with and without a history of cryptorchidism or presence of germ cell neoplasia in situ) and 20 controls with normal testis histology and LC-function. Archived testicular biopsies were re-evaluated for the presence of $\mathrm{LC}$ micronodules and Reinke crystals and the findings were correlated with testis size and serum concentrations of $L H$, follicle-stimulating hormone (FSH), testosterone, inhibin B, estradiol and sex hormone binding globulin (SHBG). RESULTS: TDS patients with bilateral LC micronodules had significantly lower concentrations of LH, FSH and inhibin B, a lower testosterone/LH-ratio and smaller testis sizes compared to TDS-patients lacking this feature. Presence of LC micronodules was correlated with a lower number of Reinke crystals, while cryptorchid testes had a significantly higher number of crystals than normally descended TDS testes. CONCLUSION: LC micronodules appear to be a compensatory mechanism caused by androgenic failure and are presumably driven by high concentrations of LH. A relative paucity of Reinke crystals in LCs within micronodules in normally descended TDS testes may be a feature of recently renewed immature Leydig cells. The increased number of Reinke crystals in LCs in testes that were either undescended at birth or are persistently undescended could indicate an impairment of LC renewal in cryptorchidism.
\end{abstract}

Key words: Cryptorchidism, Leydig cell hyperplasia, Leydig cell micronodules, Reinke crystals, Reproductive hormones, Testicular dysgenesis syndrome, TDS 


\section{INTRODUCTION}

The hypothesis of the testicular dysgenesis syndrome (TDS) proposes that testicular germ cell malignancy, poor semen quality, as well as milder forms of cryptorchidism and some cases of penile hypospadias, may be caused by disturbed intrauterine development of the testis. ${ }^{1-3}$ Impairment of Leydig cell (LC) maturation and function is believed to play a central role in the pathogenesis of TDS. LC hyperplasia, often in the form of large clusters called micronodules, is a frequent finding in patients with impaired spermatogenesis and other TDS-related disorders. ${ }^{4}$ The LC micronodules, defined as more than 15 LCs in a cross-section, have previously been associated with a low testosterone/luteinising hormone (LH)-ratio, reflecting an endocrine hypofunction. ${ }^{4,5}$ It was recently found that micronodules contain cells at different stages of differentiation with significantly increased proportions of immature LCs within micronodules in patients with germ cell tumours and in patients with Klinefelter syndrome, confirming the importance of stimulation by LH or human chorionic gonadotropin (hCG). ${ }^{6}$ Whether the aggregation of LCs is a feature linked to impaired testis development or only represents a post-pubertal compensation for lower androgen levels has not been firmly established.

LCs differentiate in a triphasic manner, with generations of LCs arising in the fetal, the postnatal and the pubertal period, respectively, with each generation being accompanied by a peak in testosterone concentration. ${ }^{7}$ Fetal LCs secrete testosterone and insulin-like peptide 3 (INSL3), which are pivotal for the masculinization of the fetus and for testicular descent. ${ }^{89}$ Adult LCs are thought to surface by recruitment and gradual maturation of spindle-shaped stem cells, which can be identified by location adjacent to peritubular cells and by expression of proteins associated with LC maturation [e.g. delta-like 1 homolog (DLK1) and INSL3] and steroidogenic function. ${ }^{6,10}$

Among morphological hallmarks of LCs in the adult testis are the polygonal cell shape and the presence of Reinke crystals (RCs) shown in Figure 1, which are usually located within the cytoplasm or-very infrequently - in the nucleus of some LCs. RCs are not found in LCs progenitors and allegedly increase in number with increasing age. ${ }^{11-13}$ In crystallographic and electron microscopy studies, the crystals are visualized as hexagonal or polygonal prisms with an interior honeycomb pattern composed of $50 \AA$ microfilaments, consistent with a proteinaceous content. ${ }^{14-16}$ A recent study provided evidence that the crystals stain specifically with antibodies for $3 \beta$-hydroxysteroid dehydrogenase ( $\beta$-HSD), which is a key enzyme needed for biosynthesis of all steroid hormones. ${ }^{16} \mathrm{RC}$ s have been reported to be absent in case studies of patients with Down's syndrome, androgen insensitivity syndrome and $17 \beta$-HSD deficiency. ${ }^{17-19}$ In LC tumours, which comprise $1-3 \%$ of all testicular neoplasms, crystals have been reported in about one third of the benign cases but are apparently lacking in most malignant LC tumours, although some negative findings may be due to tissue fixation. ${ }^{16,20-22}$

To shed light on the morphology and function of LCs in TDS patients, we set up a retrospective study of a series of patients with infertility, with or without self-reported cryptorchidism, and controls with normal LC-histology and -function. We especially focused on the presence of RCs and LC micronodules and correlated this feature with the testicular function reflected by hormonal profiling and testis size.

\section{MATERIALS AND METHODS}

\section{Study subjects}

All study subjects, including controls, were referred to the andrology clinic of the Department of Growth and Reproduction at Rigshospitalet, Denmark, within the period 1991-2010, and were identified in the department's patient database. They all underwent an examination programme, which included a summary of self-reported medical history, a physical examination including a calculation of body mass index [BMI, calculated as weight ( $\mathrm{kg}$ ) divided by height squared], a testicular ultrasonic examination to determine echo score and testis size, semen analysis and a blood sampling with reproductive hormone profiling. ${ }^{23}$ The main inclusion criterion was the availability of bilateral testicular biopsy with histological signs of TDS, such as presence of germ cell neoplasia in situ, GCNIS (originally termed carcinoma in situ, CIS testis), undifferentiated Sertoli cells, microliths and LC micronodules. ${ }^{24-26}$ Exclusion criteria included germ cell cancer with elevated plasma concentrations of 

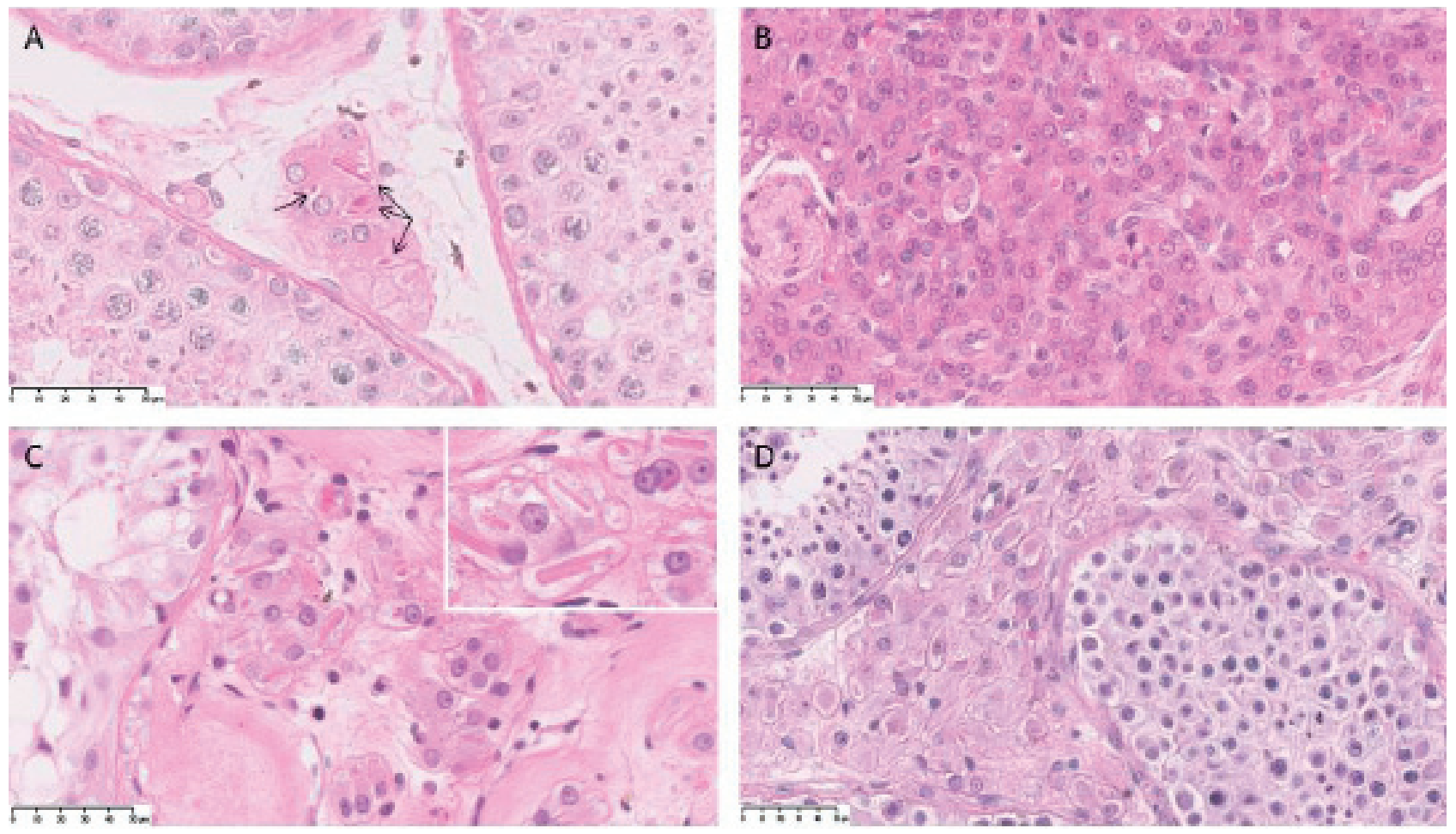

Figure 1. A: Control tissue with normal Leydig cells (LCs) and seminiferous tubules with complete spermatogenesis. Reinke crystals (RCs) are marked with arrows. B: A large micronodule that displays heterogeneous LCs with scarce crystals. The biopsy is from a man with normal karyotype and a history of bilateral cryptorchidism. At the time of biopsy both testicles were positioned in the scrotum. C: Section from an intra-abdominal testis displaying loss of germ cells, extensive hyalinisation and small clusters of LCs containing numerous RCs. The insert shows close-up on large cytoplasmic RCs. D: The normally descended contralateral testis with ongoing spermatogenesis. This testis is contralateral to the one shown in image C. In the interstitial compartment, the LCs are also clustered in micronodules but contain markedly fewer crystals than the LCs in the cryptorchid counterpart.

hCG, genetic abnormalities known to impact testis function and histology, including numerical sex chromosome aberrations or aneuploidy and deletions of the Y-chromosome, or substandard technical quality of the biopsy (formalin-fixation causing shrinkage of the testis tissue).

In total, 101 TDS patients were included in the study, comprising the following referrals: fertility problems $(\mathrm{n}=89)$, suspected testicular malignancy $(n=3)$, testicular ultrasonic microlithiasis $(n=2)$, gynecomastia $(n=1)$, scrotal pain $(n=1)$ and sperm banking prior to surgical procedures on the testes $(n=5)$. Previous andrological history included undescended testes in 76 patients, including bilateral cryptorchidism $(n=38)$, left unilateral cryptorchidism $(n=18)$ and right unilateral cryptorchidism $(\mathrm{n}=20)$, as well as inguinal hernia $(n=16)$, and testicular torsion $(n=5)$. At the time of examination, testes were in most pa- tients located within the scrotum (170 testes), except a subset with intra-abdominal testes ( 3 testes) or testes in the inguinal canal (12 testes). The location of the remaining 17 testes was not stated explicitly in the patient records. Clinical and histological examination revealed varicocele (unilateral: $n=1$, bilateral: $n=11$ ), penile hypospadias $(n=3)$ and GCNIS (unilateral: $n=12$, bilateral: $n=2$ ). Three patients were enrolled in the study in spite of carrying genetic aberrations: one case of a fragile $\mathrm{X}$-chromosome premutation, one heterozygous carrier of the CFTR $\triangle \mathrm{F} 508$ mutation and one carrier of fra(16)(q21), since these findings were not expected to influence testicular development and function.

For the control group, 20 men were selected among the patients who met the criteria of normal bilateral testis histology, serum concentrations of LH, FSH, testosterone, inhibin $\mathrm{B}$ and estradiol within the normal 
range and absence of genital malformations. These patients were referred because of obstructive azoospermia $(n=6)$, decreased semen quality without an obvious cause $(\mathrm{n}=3)$, ultrasonic testicular microlithiasis but normal testis tissue architecture in the biopsies $(n=1)$, retrograde ejaculation after extirpation of rectum because of ulcerative colitis $(\mathrm{n}=1)$ and anejaculation of unknown cause $(n=1)$. Because of difficulties in finding suitable controls with bilateral testicular biopsies, it was decided to include eight patients with congenital bilateral absence of vas deferens (all with normal testicular histology), of whom four had cystic fibrosis (three were diagnosed with mutations in one copy in the CFTR gene and one patient was suspected of carrying a rare CFTR mutation not routinely tested for in Denmark).

Previous andrological history in the control group included inguinal hernias $(\mathrm{n}=2)$ and testicular torsion $(\mathrm{n}=1)$

\section{Tissue preparation}

Testicular biopsies were excised at urology departments at Rigshospitalet or other collaborating hospitals and handled at the histology laboratory of the Department of Growth and Reproduction, Rigshospitalet, as described previously. ${ }^{27}$ The patient tissue samples were fixed in Stieve's fixative $(n=64)$, GR-fixative (a modified Steve's fixative) $(n=35)$ or Bouin's fixative $(n=2)$, respectively. Samples from the control group were fixed in Stieve's fixative $(n=15)$ or GR-fixative $(n=5)$, respectively. All tissue specimens were embedded in paraffin wax and sectioned at $4 \mu \mathrm{m}$ thicknesses using a Microm HM 355 microtome. After dewaxing and rehydration, the sections were stained with haematoxylin-eosin (HE), Periodic Acid-Schiff (PAS) and immunostained for placental-like alkaline phosphatase (PLAP), a marker of GCNIS. In this study, either HE- or PAS-stained sections were used.

\section{Histological evaluation of testicular biopsies}

Glass slides with stained serial sections were retrieved from the Department's archive. The status of having LC hyperplasia/micronodules, undifferentiated Sertoli cells, Sertoli-cell-only (SCO) tubules GCNIS was prior to the study determined by two independent routine examiners following existing guidelines and the data were retrieved from the pathology report.
In this study, selected tissue sections were reexamined using a light microscope (Zeiss, Germany) (patients, $n=73$; controls, $n=7$ ), subsequently replaced by evaluation by another microscope (Olympus, BX41) equipped with a camera live-connected to computer software (patients, $n=27$, controls $n=13$ ). The change to another methodology was prompted by introduction of new software technology that facilitated a better overview of the sections and easier counting of LCs and RCs. Some of the testis specimens $(n=14)$ were evaluated by both methods and the observations were found to be similar (data not shown).

Approximately 1500 LCs (recognised by their morphological features) per testis were registered systematically in randomly selected areas of the biopsies by one examiner, thus preventing multiple counts of the same cell. In a few cases small or traumatized biopsies made it impossible to attain the desired amount of LCs. At least three different randomly selected sections from each testis were evaluated, with the exception of one patient because of only one available section per testis. Due to a patchy distribution of LC micronodules and RCs observed within each section and heterogeneity between sections (Figure 1 ), the presence or absence of these features were noted, but not the area or extent of the clusters or the number of RCs per cell. The relative percentage of LCs containing RCs was calculated.

\section{Hormone analyses}

Serum concentrations of testosterone, $\mathrm{LH}$, folliclestimulating hormone (FSH), inhibin $\mathrm{B}$, sex hormonebinding globulin (SHBG) and estradiol were extracted from patient records. All samples had been analyzed at the Department of Growth and Reproduction, Rigshospitalet, except some hormone measurements in a few patients, and these values were excluded from the analysis. Serum concentrations of FSH, LH and SHBG were measured by time-resolved fluoroimmunoassays (Delfia ${ }^{\circledR}$, Wallac, Turku, Finland). FSH and LH had a limit of detections (LOD) of $0.05 \mathrm{U} / 1$ and intra- and inter-assay coefficients of variation (CVs) below 5\%. For SHBG, the LOD was $0.23 \mathrm{nmol} / 1$ and the intra- and inter-assay CVs were $5.1 \%$ and $7.5 \%$, respectively. Serum-testosterone was measured using a solid-phase radioimmunoassay $\left(\right.$ Coat-a-count ${ }^{\mathbb{Q}}$, Siemens Healthcare Diagnostics, LA, USA) with a LOD below 0.23 
nmol/1. The intra- and inter-assay CVs were $17 \%$ and $12.8 \%$, respectively. Inhibin B was analyzed by an enzyme-linked immunosorbent assay (03.12.1996 12.08.2008: Nigel Groome/Oxford-Bio-Innovation Ltd., Oxford, UK; from 13.08.2008: Serotec, UK), with a LOD of $20 \mathrm{pg} / \mathrm{ml}$. A concentration below 20 $\mathrm{pg} / \mathrm{ml}$ was given the value of 1 in the statistics. The intra- and inter-assay CVs of this analysis were not available. Serum estradiol was measured using a radioimmunoassay (13.09.1993 - 22.10.1998: IDS; from 23.10.1998: Pantex, CA, USA) with a detection limit of $18 \mathrm{pmol} / 1$, the intra- and inter-assay CVs were $7.5 \%$ and $14.9 \%$, respectively.

\section{Statistical analysis}

Histograms and the Shapiro-Wilk test for normality were used for testing for normality. Due to a non-normal distribution of the majority of variables, non-parametric statistics were used. Medians and interquartile ranges (IQR) were used for descriptive data, except in Table 3 where median and ranges are shown due to small numbers in a group. Betweengroup differences were tested by Kruskal-Wallis and/ or Mann Whitney tests and correlation calculations were performed using Sperman's Rho. A p-value below 0.05 was considered significant. Statistical calculations were performed using SPSS software for Windows (version 22.0).

When ultrasonic echo scores of the testes were reported as an interval, the highest value was used in the data sheet. Data regarding testes could be considered paired, but we chose also to include statistical analyses assessing testes individually, with the biological argument that each testis is influenced by its own microenvironment.

\section{Ethics}

The use of clinical data for this study was approved by the Medical Ethics Committee for the Capital Region of Denmark (permit no. H-2-2009-137) and the Danish Personal Data Protection Agency (Datatilsynet no. 2008-41-2158).

\section{RESULTS}

\section{Clinical data and reproductive hormone profiles}

The groups of TDS patients and the control patients were similar with regard to age (median 32.9 years vs. 31.9 years, respectively) and BMI $\left(25.4 \mathrm{~kg} / \mathrm{m}^{2}\right.$ vs $24.8 \mathrm{~kg} / \mathrm{m}^{2}$, respectively).

As shown in Table 1, the TDS group had significantly smaller testes, higher concentrations of LH (mainly in the cryptorchid subgroup) and FSH, lower concentrations of inhibin B and lower testosterone/ LH-ratios as compared to the controls. The patients with a history of cryptorchidism had significantly smaller volumes of the left testis, higher concentrations of LH and lower testosterone/LH-ratios compared to the non-cryptorchid patients. No significant differences in serum concentrations of estradiol, SHBG and testosterone were observed. Scrotal ultrasonic examination revealed significantly higher echo-scores in patients [median score $=3$, (IQR: $3-4)$ ] in both testes as compared to controls [score $=2,(2-3)], \mathrm{p}=0.002$ and $<0.001$ for right and left sided testes, respectively.

\section{Leydig cell histology and distribution of Reinke crystals in relation to clinical data}

In sections of patients with TDS, LCs were often arranged in micronodules of variable sizes, frequently manifesting signs of hyperplasia and hypertrophy simultaneously (Figure 1). Patients with bilateral LC micronodules had significantly smaller testis sizes compared to patients with normal LCs distribution. The only significant difference noted between having unilateral or bilateral LC micronodules was a lower testosterone/ LH-ratio in the latter group ( $\mathrm{p}=0.026)$, Table 1.

No significant difference in distribution of RCs was registered between TDS patients (including those with and without GCNIS) and controls and we found no correlation between age at biopsy and percentage of LCs containing RCs. Testes with loss of germinal cells had a significantly higher number of RCs [median 7.8 (IQR: 2.1-16.3), $\mathrm{n}=112$ ] than patient testes without SCO-tubules [4.2 (1.9-9.3), $\mathrm{n}=90], \mathrm{p}=0.034$. Furthermore, fewer RCs were observed in testes with microliths [median 3.2 (IQR: 1.3-7.8], $\mathrm{n}=32$ ) than in patient testes without this feature [6.2 (2.0-13.5), $\mathrm{n}=170], \mathrm{p}=0.053$. TDS testes with LC micronodules contained significantly fewer LCs with RCs [median 4.8 (IQR: 1.2-11.6)] than control testes [7.8 (2.023.9)], $\mathrm{p}=0.024$, and a trend in the same direction was observed if these patients were compared to the TDS patient testes with normal LCs distribution [5.7, (2.8-16.1)], $\mathrm{p}=0.061$. 
Table 1. Clinical and hormonal parameters in patients with and without a history of cryptorchidism, in patients with and without Leydig cell micronodules (LCM) and in controls. Data are presented as medians and interquartile ranges.

\begin{tabular}{|c|c|c|c|c|c|c|c|}
\hline & \multicolumn{5}{|c|}{$\begin{array}{c}\text { TDS patients } \\
\mathrm{N}=101\end{array}$} & \multirow[t]{2}{*}{$\begin{array}{c}\text { Controls } \\
\mathbf{N}=\mathbf{2 0}\end{array}$} & \multirow[t]{2}{*}{ p-values } \\
\hline & $\begin{array}{c}\text { History of } \\
\text { cryptorchidism } \\
N=76\end{array}$ & $\begin{array}{c}\text { Non- } \\
\text { cryptorchid } \\
\mathrm{N}=25\end{array}$ & $\begin{array}{c}\text { Bilateral } \\
\text { LCM } \\
\mathrm{N}=41\end{array}$ & $\begin{array}{c}\text { Unilateral } \\
\text { LCM } \\
\mathbf{N}=\mathbf{1 7}\end{array}$ & $\begin{array}{c}\text { Absence of } \\
\text { LCM } \\
\mathrm{N}=43\end{array}$ & & \\
\hline $\begin{array}{l}\text { Size, right testis } \\
(\mathrm{ml})\end{array}$ & $\begin{array}{c}8.5 \\
(5.7-11.0) \\
n=56\end{array}$ & $\begin{array}{c}8.3 \\
(6.1-12.0) \\
n=24\end{array}$ & $\begin{array}{c}7.6 \\
(5.6-10.2) \\
n=33\end{array}$ & $\begin{array}{c}6.3 \\
(5.0-8.7) \\
n=16\end{array}$ & $\begin{array}{c}11.0 \\
(6.5-15.1) \\
n=31\end{array}$ & $\begin{array}{c}15.0 \\
(11.5-20.0) \\
\mathrm{n}=15\end{array}$ & $\begin{array}{l}a: \mathrm{p}=0.709 \\
b: \mathrm{p}=0.254 \\
c: \mathrm{p}=0.007 \\
d: \mathrm{p}=0.002\end{array}$ \\
\hline $\begin{array}{l}\text { Size, left testis } \\
(\mathrm{ml})\end{array}$ & $\begin{array}{c}6.5 \\
(4.6-9.6) \\
n=59\end{array}$ & $\begin{array}{c}9.3 \\
(6.4-12.6) \\
n=24\end{array}$ & $\begin{array}{c}6.6 \\
(4.5-9.1) \\
n=34\end{array}$ & $\begin{array}{c}6.3 \\
(5.4-7.8) \\
n=16\end{array}$ & $\begin{array}{c}9.7 \\
(5.1-13.8) \\
n=33\end{array}$ & $\begin{array}{c}13.7 \\
(11.5-15.9) \\
n=14\end{array}$ & $\begin{array}{l}a: \mathrm{p}=0.021 \\
b: \mathrm{p}=0.901 \\
c: \mathrm{p}=0.012 \\
d: \mathrm{p}=0.044\end{array}$ \\
\hline LH (U/1) & $\begin{array}{c}5.3 \\
(3.7-6.5) \\
n=76\end{array}$ & $\begin{array}{c}4.0 \\
(2.6-4.8) \\
n=24\end{array}$ & $\begin{array}{c}5.9 \\
(4.2-6.7) \\
n=41\end{array}$ & $\begin{array}{c}4.7 \\
(3.9-6.1) \\
n=17\end{array}$ & $\begin{array}{c}4.0 \\
(2.5-5.4) \\
n=42\end{array}$ & $\begin{array}{c}2.9 \\
(2.3-3.8) \\
n=17\end{array}$ & $\begin{array}{l}a: \mathrm{p}=0.010 \\
b: \mathrm{p}=0.256 \\
c: \mathrm{p}<0.001 \\
d: \mathrm{p}=0.043\end{array}$ \\
\hline FSH (U/l) & $\begin{array}{c}11.6 \\
(6.7-18.4) \\
n=76\end{array}$ & $\begin{array}{c}8.7 \\
(5.1-14.7) \\
n=24\end{array}$ & $\begin{array}{c}13.1 \\
(8.1-20.0) \\
n=41\end{array}$ & $\begin{array}{c}12.7 \\
(7.9-15.4) \\
n=17\end{array}$ & $\begin{array}{c}7.5 \\
(4.9-13.9) \\
n=42\end{array}$ & $\begin{array}{c}3.1 \\
(2.5-4.9) \\
n=17\end{array}$ & $\begin{array}{l}a: \mathrm{p}=0.201 \\
b: \mathrm{p}=0.500 \\
c: \mathrm{p}=0.006 \\
d: \mathrm{p}=0.039\end{array}$ \\
\hline $\begin{array}{l}\text { Inhibin B } \\
(\mathrm{pg} / \mathrm{ml})\end{array}$ & $\begin{array}{c}75 \\
(32.0-121.0) \\
n=71\end{array}$ & $\begin{array}{c}92 \\
(42.5-147.0) \\
n=21\end{array}$ & $\begin{array}{c}50.0 \\
(26.0-92.0) \\
n=39\end{array}$ & $\begin{array}{c}48.0 \\
(35.3-106.0) \\
n=14\end{array}$ & $\begin{array}{c}99.0 \\
(58.0-153.0) \\
n=39\end{array}$ & $\begin{array}{c}192.5 \\
(138.3-274.3) \\
n=12\end{array}$ & $\begin{array}{l}a: \mathrm{p}=0.261 \\
b: \mathrm{p}=0.746 \\
c: \mathrm{p}=0.006 \\
d: \mathrm{p}=0.072\end{array}$ \\
\hline T/LH-ratio & $\begin{array}{c}2.9 \\
(1.9-4.1) \\
n=76\end{array}$ & $\begin{array}{c}3.8 \\
(3.1-5.1) \\
n=24\end{array}$ & $\begin{array}{c}2.5 \\
(1.7-3.5) \\
n=41\end{array}$ & $\begin{array}{c}3.2 \\
(2.9-3.7) \\
n=17\end{array}$ & $\begin{array}{c}3.9 \\
(2.8-5.2) \\
n=42\end{array}$ & $\begin{array}{c}4.7 \\
(3.8-6.8) \\
n=17\end{array}$ & $\begin{array}{l}a: \mathrm{p}=0.007 \\
b: \mathrm{p}=0.026 \\
c: \mathrm{p}<0.001 \\
d: \mathrm{p}=0.132\end{array}$ \\
\hline $\begin{array}{l}\text { Testosterone } \\
(\mathrm{nmol} / \mathrm{L})\end{array}$ & $\begin{array}{c}14.5 \\
(10.5-17.9) \\
n=76\end{array}$ & $\begin{array}{c}14.1 \\
(12.2-15.9) \\
n=24\end{array}$ & $\begin{array}{c}13.6 \\
(10.6-16.9) \\
n=41\end{array}$ & $\begin{array}{c}16 \\
(12.7-20.0) \\
n=17\end{array}$ & $\begin{array}{c}13.8 \\
(10.6-17.9) \\
n=42)\end{array}$ & $\begin{array}{c}15.2 \\
(11.2-19.2) \\
n=17\end{array}$ & $\begin{array}{l}a: \mathrm{p}=0.850 \\
b, c, d^{*}: \\
\mathrm{p}=0.144\end{array}$ \\
\hline $\begin{array}{l}\text { Estradiol } \\
(\mathrm{pmol} / \mathrm{l})\end{array}$ & $\begin{array}{c}75.5 \\
(58.3-101.0) \\
n=76\end{array}$ & $\begin{array}{c}76.0 \\
(67.5-95.8) \\
n=24\end{array}$ & $\begin{array}{c}75.0 \\
(49.0-83.5) \\
n=41\end{array}$ & $\begin{array}{c}85.0 \\
(71.5-101.5) \\
n=17\end{array}$ & $\begin{array}{c}79.5 \\
(66.8-105.0) \\
n=42\end{array}$ & $\begin{array}{c}68.0 \\
(57.3-82.8) \\
n=16\end{array}$ & $\begin{array}{l}a: \mathrm{p}=0.793 \\
b, c, d^{*}: \\
\mathrm{p}=0.084\end{array}$ \\
\hline $\begin{array}{l}\text { SHBG } \\
(\mathrm{nmol} / \mathrm{l})\end{array}$ & $\begin{array}{c}29.0 \\
(21.3-41.5) \\
n=76\end{array}$ & $\begin{array}{c}28.5 \\
(24.3-35.5) \\
n=24\end{array}$ & $\begin{array}{c}29.0 \\
(21.0-39.0) \\
n=41\end{array}$ & $\begin{array}{c}35.0 \\
(25.5-42.5) \\
n=17\end{array}$ & $\begin{array}{c}29.0 \\
(23.0-35.8) \\
n=42\end{array}$ & $\begin{array}{c}32.0 \\
(23.3-37.8) \\
n=16\end{array}$ & $\begin{array}{l}a: \mathrm{p}=0.840 \\
b, c, d^{*}: \\
\mathrm{p}=0.522\end{array}$ \\
\hline
\end{tabular}

a: Difference between cryptorchid and non-cryptorchid patients; b: Difference between bilateral and unilateral LCM; c: Difference between bilateral LCM and absence of LCM; d: Difference between unilateral LCM and absence of LCM.

*Kruskall-Wallis test.

Presence of LC hyperplasia and clustering was significantly correlated to the presence or history of cryptorchidism $\left(r_{2}=0.14, p=0.043\right)$. Undescended testes containing $\mathrm{LC}$ micronodules had a significantly lower amount of LCs with RCs [median 6.1 (IQR: 1.8-13.2)] than cryptorchid testes without LC clusters [8.4 [3.3-18.6)], $\mathrm{p}=0.043$. As shown in Table 2, the relative percentage of LCs containing RCs was lower in 
all normally descended TDS testes as compared to all testes with a history of cryptorchidism $(\mathrm{p}=0.010)$ and to control testes $(p=0.016)$, respectively. Furthermore, normally descended TDS testes without a cryptorchid counterpart were found to have significantly fewer $\mathrm{RCs}$ than unilateral cryptorchid testes $(\mathrm{p}=0.020)$ and control testes $(\mathrm{p}=0.030)$, respectively. Descended TDS testes with cryptorchid counterparts contained significantly fewer RCs than unilateral cryptorchid testes $(p=0.021)$ and control testes $(p=0.045)$, respectively.

As shown in Table 3, three patients had testes located intra-abdominally at the time of the biopsy and these specimens contained a significantly higher number of RC-containing LCs compared to patient testes with a high $(\mathrm{p}=0.003)$ or a low $(\mathrm{p}=0.018)$ scrotal position, respectively. Inguinally located testes had a significantly higher number of LCs with RCs than

Table 2. The distribution of Reinke crystals (RCs) in the patient subgroups depending on the history of cryptorchidism, in comparison to the controls. Data are presented as medians and interquartile ranges.

\begin{tabular}{lc}
\hline History of testicular descent & $\begin{array}{c}\text { Percentage of } \\
\text { counted LCs } \\
\text { containing RCs }\end{array}$ \\
\hline TDS testes that were cryptorchid at birth & \\
All $(\mathrm{n}=114)$ & $7.4(2.2-16.1)$ \\
Bilateral $(\mathrm{n}=76)$ & $6.6(1.8-15.2)$ \\
Unilateral $(\mathrm{n}=38)$ & $8.4(2.9-20.8)$ \\
Normally descended TDS testes & \\
All $(\mathrm{n}=88)$ & $3.9(1.7-9.5)$ \\
With a cryptorchid counterpart $(\mathrm{n}=38)$ & $3.9(1.7-9.4)$ \\
Without a cryptorchid counterpart $(\mathrm{n}=50)$ & $4.0(1.0-10.0)$ \\
Control testes $(\mathrm{n}=40)$ & $7.8(2.0-23.9)$ \\
\hline
\end{tabular}

Table 3. Percentage of counted Leydig cells (LCs) with Reinke crystals (RCs) in relation to anatomical position of patient testes at the time of the physical examination. Data are shown as medians and ranges.

\begin{tabular}{lc}
\hline Testis position & $\begin{array}{c}\text { Percentage of counted LCs } \\
\text { containing RCs }\end{array}$ \\
\hline Scrotum, low $(\mathrm{n}=128)$ & $4.3(0-39.7)$ \\
Scrotum, high $(\mathrm{n}=42)$ & $5.6(0.06-22.2)$ \\
Inguinal canal $(\mathrm{n}=12)$ & $9.5(1.79-31.9)$ \\
Intra-abdominal $(\mathrm{n}=3)$ & $22.3(16.06-25.5)$ \\
\hline
\end{tabular}

the TDS patient testes positioned high $(\mathrm{p}=0.026)$ or low in the scrotum $(\mathrm{p}=0.028)$.

\section{DISCUSSION}

In this study, we expanded the existing knowledge on LCs clustering into micronodules, the distribution of RCs in these cells and an association with hormonal function in adult patients with signs of testicular dysgenesis. The main finding of this study is the relative paucity of RCs in LC clusters, but with a paradoxical increase in the RC numbers in cryptorchid testes. Surprisingly, the distribution of RCs did not correlate with the severity of androgenic dysfunction in TDS patients with LC micronodules, which was reflected in this study by lower serum testosterone/LH-ratios, decreased serum inhibin B and by reduced testis size, in line with our previous study. ${ }^{5}$ In another study, we have demonstrated that $\mathrm{LC}$ micronodules in patients with TDS and Klinefelter syndrome, a condition known for very large clusters of LCs, contain proportionally higher numbers of immature LCs due to an increased renewal of the LCs stimulated by LH. ${ }^{6}$ The data in the present study provides evidence that the scarcity of RCs may be a characteristic feature of immature adult LCs, this hypothesis being in concert with previous studies of hyperplastic LCs in infertile patients and men with Klinefelter syndrome. ${ }^{28-31}$

In this study we re-investigated a previously reported finding that the number of RCs in undescended testes may be significantly greater than in normally descended testes. ${ }^{15}$ We have confirmed a high number of RC-containing LCs in patients with a history of undescended testes, and revealed an interesting pattern of an increasing proportion of the RC-containing cells with the more cranial testis position and with significantly greater abundance of RCs in intra-abdominal testes. This is in line with influence of temperature, suggested by Kozina's study. ${ }^{15}$ Surprisingly, in our study testes that were cryptorchid at birth, and especially unilaterally undescended testes, seemed to contain higher numbers of RCs as compared to normally descended testes in TDS patients. It was unexpected because the specimens from men with a history of cryptorchidism often contain LC micronodules. But when assessing specimens of all men who reported ever being cryptorchid, those with micronodules had 
significantly less RCs-containing LCs than those without, this implying it might not be a chance finding in spite of being seemingly contradictory. We have no ready explanation, but we speculate that the relative paucity of RCs in micronodules occurring in TDS patients may reflect an increase in recruitment of immature LCs from their immature stem cells which do not contain the crystals. In a previous study, the heterogeneity of LCs arranged in micronodules was confirmed by the distinct immunohistochemical markers for different stages of differentiation. ${ }^{6}$ A marker of immature endocrine cells, DLK1, was predominantly found in progenitor cells, whereas INSL3, a well-known marker of LC maturity, was abundant in mature polygonal LCs. ${ }^{32}$ The presence of DLK1 was positively correlated to the total number of LCs and up-regulated in the TDS patients, a phenomenon consistent with immaturity of LCs arranged in clusters. ${ }^{6}$ We propose that the renewal from LC stem cells may be impaired in TDS patients but influenced by the temperature, hence the observed difference between the descended and undescended testis. However, we interpret these results with caution, since our study has some shortcomings: the history of cryptorchidism was self-reported and for obvious reasons it was impossible to find enough control tissue specimens from truly healthy controls. After the routine histopathological assessment of testicular biopsies very little or no tissue was left, thus we were unable to perform a more objective stereological evaluation of $\mathrm{LC}$ and $\mathrm{RC}$ numbers. It was also impossible to amend our data with an assessment of LC differentiation status by DLK1/INSL3 expression pattern because of incompatibility of the antibodies with the fixation method used for routine biopsies. On the other hand, the fixation methods used in our laboratory allowed very good assessment of the morphology of the testicular tissue, including RCs (Figure 1) and apparently did not dissolve the crystals, which is suspected to be the case in some formalin-fixed specimens. ${ }^{16}$

The relative paucity of RCs in immature LCs within the micronodules may be linked to the impaired steroidogenesis, which is one of the hallmarks of TDS. ${ }^{2}$ However, more than one circumstance speaks against this: only a minority of adult LCs contain RCs and the crystals are absent in fetal LCs which are known to secrete vast amounts of androgens. Furthermore, absence of RCs in patients with androgen insensitivity syndrome points to other explanations, given that the androgen production is not compromised in these patients. ${ }^{18,33}$ Some researchers have suggested that RCs are composed of proteins, as they can be identified by some antibodies, e.g. most recently, the reported reaction with $3 \beta-\mathrm{HSD}$, but the tendency of unspecific positive reactions in immunohistochemistry is well known. ${ }^{16}$ Thus, the RCs may be considered a biomarker of the proper function of mature adult LCs, but their identity remains unknown.

In conclusion, this study presents new evidence of the scarcity of RCs within LCs arranged in micronodules associated with TDS, most likely due to an increased number of immature LCs, which have lower numbers of RCs than the mature adult LCs, if any. Our finding of the positive association between the occurrence of Reinke crystals and the position of the testes points to a decreased LC renewal in undescended testes. Further studies are needed to corroborate this hypothesis.

\section{ACKNOWLEDGEMENTS}

We would like to thank senior scientists Kristian Almstrup, for his help with imaging technique, and John Erik Nielsen, for his advice concerning histology stains. We are also grateful for the help from the staff of our hormone and histology laboratories.

\section{REFERENCES}

1. Skakkebaek NE, Rajpert-De Meyts E, Main KM, 2001 Testicular dysgenesis syndrome: an increasingly common developmental disorder with environmental aspects. Hum Reprod 16: 972-978.

2. Skakkebæk NE, Rajpert-De Meyts E, Buck Louis GM, et al, 2016 Male reproductive disorders and fertility trends: Influences of Environment and Genetic Susceptibility. Physiol Rev 96: 55-97.

3. Jørgensen N, Rajpert-De Meyts E, Main KM, Skakkebaek NE, 2010 Testicular dysgenesis syndrome comprises some but not all cases of hypospadias and impaired spermatogenesis. Int J Androl 33: 298-303.

4. Joensen UN, Jørgensen N, Rajpert-De Meyts E, Skakkebaek NE, 2008 Testicular dysgenesis syndrome and Leydig cell function. Basic Clin Pharmacol Toxicol 102: $155-161$.

5. Holm M, Rajpert-De Meyts E, Andersson AM, Skakkebaek NE, 2003 Leydig cell micronodules are a common 
finding in testicular biopsies from men with impaired spermatogenesis and are associated with decreased testosterone/LH ratio. J Pathol 199: 378-386.

6. Lottrup G, Nielsen JE, Maroun LL et al, 2014 Expression patterns of DLK1 and INSL3 identify stages of Leydig cell differentiation during normal development and in testicular pathologies, including testicular cancer and Klinefelter syndrome. Hum Reprod 29: 1637-1650.

7. Prince FP, 2001 The triphasic nature of Leydig cell development in humans, and comments on nomenclature. J Endocrinol 168: 213-216.

8. Zimmermann S, Steding G, Emmen JM, et al, 1999 Targeted disruption of the Ins13 gene causes bilateral cryptorchidism. Mol Endocrinol 13: 681-691.

9. Bay K, Main KM, Toppari J, Skakkebæk NE, 2011 Testicular descent: INSL3, testosterone, genes and the intrauterine milieu. Nat Rev Urol 8: 187-196.

10. Landreh L, Spinnler K, Schubert K, et al, 2014 Human testicular peritubular cells host putative stem Leydig cells with steroidogenic capacity. J Clin Endocrinol Metab 99: E1227-1235.

11. Reinke F, 1896 Beiträge zur histologie des Menschen. I. Krystalloidbildung in den interstitiellen Zellen des menschlichen Hodens. Arch Mikrosk Anat 47: 34-44.

12. Mori H, Fukunishi R, Fujii M, Hataji K, Shiraishi T, Matsumoto K, 1978 Stereological analysis of Reinke's crystals in human Leydig cells. Virchows Arch A. Pathol Anat Histol 380: 1-9.

13. Paniagua R, Amat P, Nistal M, Martin A, 1986 Ultrastructure of Leydig cells in human ageing testes. J Anat 146: $173-183$.

14. Nagano T, Otsuki I, 1971 Reinvestigation of the fine structure of Reinke's crystal in the human testicular interstitial cell. J Cell Biol 51: 148-161.

15. Kozina V, Geist D, Kubinová L, et al, 2011 Visualization of Reinke's crystals in normal and cryptorchid testis. Histochem Cell Biol 135: 215-228.

16. Mesa H, Gilles S, Smith S, Dachel S, Larson W, Manivel JC, 2015 The mystery of the vanishing Reinke crystals. Hum Pathol 46: 600-606.

17. Sasagawa I, Nakada T, Kubota Y et al, 1995 Ultrastructure of Leydig cells in Down's syndrome. Int Urol and Nephrol 27: 585-591.

18. Aumüller G, Peter S, 1986 Immunohistochemical and ultrastructural study of Sertoli cells in androgen insensitivity. Int J Androl 9: 99-108.
19. Longo FJ, Coleman SA, Givens JR, 1975 Ultrastructural analysis of the testes in male pseudohermaphrodism reductase. Am J C Pathol 64: 145-154.

20. Al-Agha OM, Axiotis CA, 2007 An in-depth look at Leydig cell tumor of the testis. Arch Pathol Lab Med 131: 311-317.

21. Kim I, Young RH, Scully RE, 1985 Leydig cell tumors of the testis. A clinicopathological analysis of 40 cases and review of the literature. Am J Surg Pathol 9: 177-192.

22. Feldman PS, Kovacs K, Horvath E, Adelson GL, 1982 Malignant Leydig cell tumor: clinical, histologic and electron microscopic features. Cancer 49: 714-721.

23. Lenz S, Thomsen JK, Giwercman A, Hertel NT, Hertz J, Skakkebaek NE, 1994 Ultrasonic texture and volume of testicles in infertile men. Hum Reprod 9: 878-881.

24. Skakkebaek NE, 1972 Possible carcinoma-in-situ of the testis. Lancet 2: 516-517.

25. Ulbright TM, Amin MB, Balzer B et al, 2016 Germ cell tumours. In: Moch H, Humphrey PA, Reuter VE, Ulbright TM (Eds). WHO classification of tumours of the urinary system and male genital organs, 4th Edition. IARC Press, pp, 189-226.

26. Hoei-Hansen CE, Holm M, Rajpert-De Meyts E, Skakkebæk NE, 2003 Histological evidence of testicular dysgenesis in contralateral biopsies of 218 patients with testicular germ cell cancer. J Pathol 200: 370-374.

27. McLachlan R, Rajpert-De Meyts E, Hoei-Hansen C, De Kretser DM, Skakkebaek NE, 2007 Histological evaluation of the human testis: approaches to optimizing the clinical value of assessment: Mini review. Hum Reprod 22: 2-16.

28. Söderström KO, 1986 Leydig cell hyperplasia. Arch Androl 17: 57-65.

29. Naughton CK, Nadler RB, Basler JW, Humphrey PA, 1998 Leydig cell hyperplasia. Br J Urol 81: 282-289.

30. Ježek D, Geist D, Banek LJ et al, 2007 Reinke's Crystals in Infertile Patients. Acta Clin Croat 46: 220.

31. Paniagua R, Nistal M, Bravo MP, 1984 Leydig cell types in primary testicular disorders. Hum Pathol 15: 181-190.

32. Ivell R, Wade JD, Anand-Ivell R, 2013 INSL3 as a biomarker of Leydig cell functionality. Biol Reprod 88: 147.

33. Justrabo E, Cabanne F, Michiels R, et al, 1978 A complete form of testicular feminisation syndrome; a light and electron microscopy study. J Pathol 126: 165-171. 